\title{
ANALISIS PADA SISTEM INFORMASI AKADEMIK MAHASISWA MENGGUNAKAN METODE SYSTEM USABILITY SCALE
}

\section{(THE ANALYSIS ON STUDENTS 'ACADEMIC INFORMATION SYSTEM USING USABILITY SCALE SYSTEM)}

\author{
Wresni Anggraini, Nofirza, Reski Mai Candra, dan Widad Ulfika Sari \\ Fakultas Sains dan Teknologi, UIN Sultan Syarif Kasim Riau, \\ Jl. HR. Soebrantas No. 155 Simpang Baru, Pekanbaru, Indonesia 28293 \\ email: widadulfika1@gmail.com
}

\begin{abstract}
Abstrak
Penelitian ini bertujuan untuk mengidentifikasi permasalahan pada Sistem Informasi Akademik Mahasiswa (SIAM), mengetahui tingkat usability-nya, dan memberikan rekomendasi perbaikan SIAM. Penelitian ini dilakukan di Universitas Muhammadiyah Riau mulai Februari hingga Juli 2019. Tahap awal pengumpulan data dilakukan dengan melakukan observasi langsung terhadap objek penelitian yaitu Sistem Informasi Akademik Mahasiswa (SIAM) UMRI. Sampel diambil menggunakan metode random sampling. Sebanyak 4.623 mahasiswa aktif pengguna SIAM Universitas Muhammadiyah Riau terpilih menjadi sampel dalam penelitian ini. Penelitian ini dilakukan dengan menggunakan metode System Usability Scale (SUS) untuk mengetahui tingkat usability, mengidentifikasi permasalahan, dan memberi rekomendasi perbaikan SIAM. Hasil penelitian menunjukan bahwa SIAM sudah acceptable atau dapat diterima oleh penggunanya dan memiliki skala nilai $\mathrm{C}+$ dan memiliki rating good; dan fitur SIAM belum dirancang dengan baik; dan SIAM memiliki banyak inkonsistensi. Beberapa rekomendasi perbaikan dari beberapa pihak diharapkan dapat dijadikan sebagai rujukan bagi tim pengembang sistem dalam melakukan perbaikan usability system sehingga SIAM memiliki tingkat usability yang tinggi dan dapat mencapai kepuasan pengguna.
\end{abstract}

Kata kunci: SIAM, sistem informasi, system usability scale, usability

\begin{abstract}
This study was aimed at identifying the problems in the Student Academic Information System (SAIS), determining the level of usability, and providing recommendations for the improvement of SAIS. This study was conducted at Muhammadiyah Riau University from February to July 2019. The initial stage of data collection was carried out by direct observation of the research object, namely the UMRI SIAS. In determining the sample, from the random sampling, the 4,623 active students were taken a part in SAIS, Muhammadiyah University of Riau. This study was conducted using the System Usability Scale (SUS) method to determine the level of usability, identify problems, and provide recommendations for improvements to SIAS. The results show that SIAS is acceptable and feasible to its users. SIAS got C+ (good) rating scale since its functions and features are not well designed and has many inconsistencies. Some recommendations for improvement from several parties are expected to be used as a reference for the system development team in improving the usability of the system so that SIAS get a higher level of usability and can achieve user satisfaction.
\end{abstract}

Keywords: SAIS, information systems, system usability scale, usability 


\section{PENDAHULUAN}

Teknologi informasi dan komunikasi saat ini berkembang sangat pesat di segala bidang. Salah satu contoh penggunaan teknologi informasi dan komunikasi adalah penggunaan sistem informasi pada setiap perguruan tinggi. Sistem informasi merupakan salah satu faktor yang sangat penting bagi sebuah perguruan tinggi untuk meningkatkan efisiensi dan efektivitas seluruh kegiatan akademik dan nonakademik sehingga dapat meningkatkan mutu perguruan tinggi tersebut.

Adanya perkembangan yang sangat pesat ini, salah satu perguruan tinggi di Indonesia yaitu Universitas Muhammadiyah Riau juga memiliki sistem informasi yang terintegrasi yang dapat mendukung proses manajemen informasi yang cepat dan real time. Sistem informasi akademik, kemahasiswaan sehingga proses pendaftaran mahasiswa baru, seluruhnya sudah diintegrasikan dengan sistem yang real time dan online serta dapat diakses dimana saja dan kapan saja (umri.ac.id, 2011).

Sistem informasi akademik merupakan salah satu penerapan sistem informasi di perguruan tinggi. Sistem Informasi Akademik adalah sistem yang dirancang dengan tujuan untuk memenuhi kebutuhan institusi pendidikan yang menginginkan layanan pendidikan yang terkomputerisasi untuk meningkatkan kinerja, kualitas pelayanan, kualitas sumber daya manusia, dan daya saing yang dihasilkannya (Siagian \& Effiyaldi, 2018).

Universitas Muhammadiyah Riau menerapkan sistem informasi akademik yang bernama Sistem Informasi Akademik Mahasiswa (SIAM). SIAM merupakan sistem informasi yang berkaitan dengan pengolahan data-data akademik dan dapat mempermudah proses kegiatan akademik mahasiswa seperti mengisi kartu rencana studi (KRS), melihat jadwal perkuliahan, melihat kartu hasil studi dan transkip nilai, melihat data pembayaran uang kuliah, dan mencetak kartu ujian (umri.ac.id, 2011).

Tidak dapat dipungkiri bahwa sistem informasi akademik sangat mempengaruhi proses berjalannya kegiatan akademik. Kelancaran proses akademik dipengaruhi oleh kualitas sistem informasi yang dimiliki. Kualitas dan tingkat penerimaan suatu sistem tergantung pada kemudahan penggunaan sistem. Suatu sistem informasi dapat dikatakan berhasil, salah satunya jika sistem informasi tersebut dapat digunakan dengan mudah dan dapat memenuhi kebutuhan pengguna (Widiatmoko, Suyanto, \& Sofyan, 2015). Tingkat usability menentukan sistem tersebut memiliki manfaat, dapat diterima oleh user, dan dapat bertahan lama dalam penggunaannya (Aelani \& Falahah, 2012).

Kuesioner disebarkan kepada mahasiswa UMRI sebanyak 30 orang untuk melihat penilaian mereka terhadap fungsi- 
fungsi SIAM sehingga dapat diketahui permasalahan yang ada. Rekapitulasi hasil kuesioner penilaian fungsi SIAM disajikan pada Tabel 1.

Tabel 1

Rekapitulasi Kuesioner Fungsi SIAM

\begin{tabular}{ccccccccc}
\hline \multirow{2}{*}{ Responden } & \multicolumn{7}{c}{ Fungsi SIAM } \\
\cline { 2 - 8 } & $\mathbf{1}$ & $\mathbf{2}$ & $\mathbf{3}$ & $\mathbf{4}$ & $\mathbf{5}$ & $\mathbf{6}$ & $\mathbf{7}$ & $\mathbf{8}$ \\
\hline 1 & 4 & 4 & 4 & 4 & 4 & 3 & 4 & 2 \\
2 & 4 & 4 & 4 & 4 & 4 & 4 & 4 & 3 \\
3 & 4 & 4 & 4 & 4 & 4 & 2 & 4 & 2 \\
4 & 4 & 4 & 4 & 4 & 4 & 4 & 2 & 2 \\
5 & 4 & 4 & 4 & 4 & 4 & 4 & 4 & 2 \\
6 & 4 & 4 & 2 & 4 & 4 & 4 & 4 & 2 \\
7 & 4 & 4 & 4 & 4 & 4 & 2 & 2 & 2 \\
8 & 5 & 4 & 2 & 4 & 4 & 2 & 2 & 4 \\
9 & 4 & 4 & 4 & 4 & 4 & 3 & 4 & 2 \\
10 & 4 & 4 & 3 & 4 & 3 & 3 & 4 & 2 \\
11 & 4 & 4 & 2 & 4 & 4 & 2 & 4 & 2 \\
12 & 4 & 4 & 2 & 4 & 4 & 4 & 4 & 2 \\
13 & 4 & 4 & 2 & 4 & 2 & 3 & 2 & 3 \\
14 & 4 & 4 & 2 & 3 & 3 & 2 & 4 & 3 \\
15 & 4 & 4 & 2 & 4 & 4 & 2 & 2 & 3 \\
16 & 4 & 4 & 3 & 4 & 4 & 3 & 2 & 3 \\
17 & 4 & 4 & 2 & 4 & 4 & 4 & 4 & 3 \\
18 & 4 & 4 & 2 & 4 & 2 & 2 & 4 & 3 \\
19 & 4 & 4 & 2 & 3 & 3 & 2 & 4 & 3 \\
20 & 4 & 4 & 4 & 4 & 4 & 2 & 4 & 2 \\
21 & 4 & 4 & 2 & 4 & 2 & 3 & 2 & 3 \\
22 & 4 & 4 & 4 & 4 & 4 & 3 & 4 & 2 \\
23 & 5 & 5 & 5 & 5 & 5 & 5 & 5 & 5 \\
24 & 4 & 4 & 4 & 4 & 4 & 4 & 4 & 2 \\
25 & 4 & 4 & 4 & 4 & 4 & 4 & 2 & 3 \\
26 & 4 & 4 & 4 & 4 & 4 & 2 & 4 & 4 \\
27 & 4 & 4 & 4 & 4 & 4 & 2 & 4 & 3 \\
28 & 5 & 5 & 5 & 5 & 5 & 5 & 5 & 3 \\
29 & 4 & 4 & 4 & 4 & 4 & 4 & 4 & 4 \\
30 & 4 & 4 & 2 & 4 & 4 & 4 & 2 & 4 \\
\hline & & & & & & &
\end{tabular}

Tabel 1 menunjukkan penilaian mahasiswa terhadap fungsi SIAM yaitu: melihat informasi data mahasiswa, melihat transkrip nilai, mengisi kartu rencana studi (KRS), melihat kartu hasil studi (KHS), mencetak kartu ujian, melihat jadwal perkuliahan, melihat histori pembayaran uang kuliah, dan fitur menu bantuan. Tabel 1 menunjukkan bahwa mahasiswa masih sering mengalami kendala-kendala yang berhubungan dengan tidak berjalannya fungsi SIAM dengan baik. Berdasarkan kuesioner tersebut, dapat diketahui bahwa terdapat penilaian "tidak baik" terhadap beberapa fungsi SIAM yaitu $40 \%$ pada fungsi mengisi KRS; $10 \%$ pada fungsi mencetak kartu ujian; 36,67\% pada fungsi melihat jadwal perkuliahan; 30\% pada fungsi melihat histori pembayaran uang kuliah; dan 43,33\% pada fitur menu bantuan.

Pada umumnya dalam pengembangan dan implementasi sebuah sistem informasi atau software yang dilakukan oleh banyak pihak, jarang sekali dilakukan pengujian usability. Kebanyakan dari sistem informasi langsung diterapkan dan digunakan tanpa pernah diteliti sejauh mana usability sistem tersebut menurut penggunaannya (Aelani \& Falahah, 2012).

Dengan adanya pernyataan di atas yang menyertai permasalahan-permasalahan pada SIAM, diperlukan adanya pengukuran usability terhadap sistem tersebut untuk mengetahui keadaan sistem, evaluasi 
yang paling relevan untuk mengetahui kekurangan-kekurangan pada sistem, dan mengetahui tingkat usability pada sistem. Mengukur usability berarti mengukur tingkat efektifitas, efisiensi, dan kepuasan user. Pengukuran usability dapat dilakukan dengan menggunakan metode System Usability Scale (SUS).

Metode SUS dikembangkan oleh John Brooke sejak 1986 sebagai sebuah pengukuran usability yang "quick and dirty" (H. N., Santoso, \& Ferdiana, 2015). SUS merupakan kuesioner yang dapat digunakan untuk mengukur usability sistem komputer menurut sudut pandang subyektif pengguna (Brooke, 2013).

Dalam penelitian ini dilakukan pengukuran usability terhadap SIAM Universitas Muhammadiyah Riau meng- gunakan metode SUS dengan tujuan untuk mengetahui tingkat usability, mengidentifikasi permasalahan, dan memberi rekomendasi perbaikan SIAM. Hasil dari penelitian ini diharapkan dapat dijadikan sebagai tolak ukur bagi tim pengembang dalam melakukan pengembangan SIAM sehingga SIAM dapat memberikan kepuasan terhadap seluruh user-nya.

\section{METODE PENELITIAN}

Penelitian ini dilakukan di Universitas Muhammadiyah Riau mulai Februari hingga Juli 2019. Tahap awal pengumpulan data dilakukan dengan melakukan observasi langsung terhadap objek penelitian yaitu SIAM UMRI. Gambar 1 menunjukkan bentuk halaman depan SIAM.

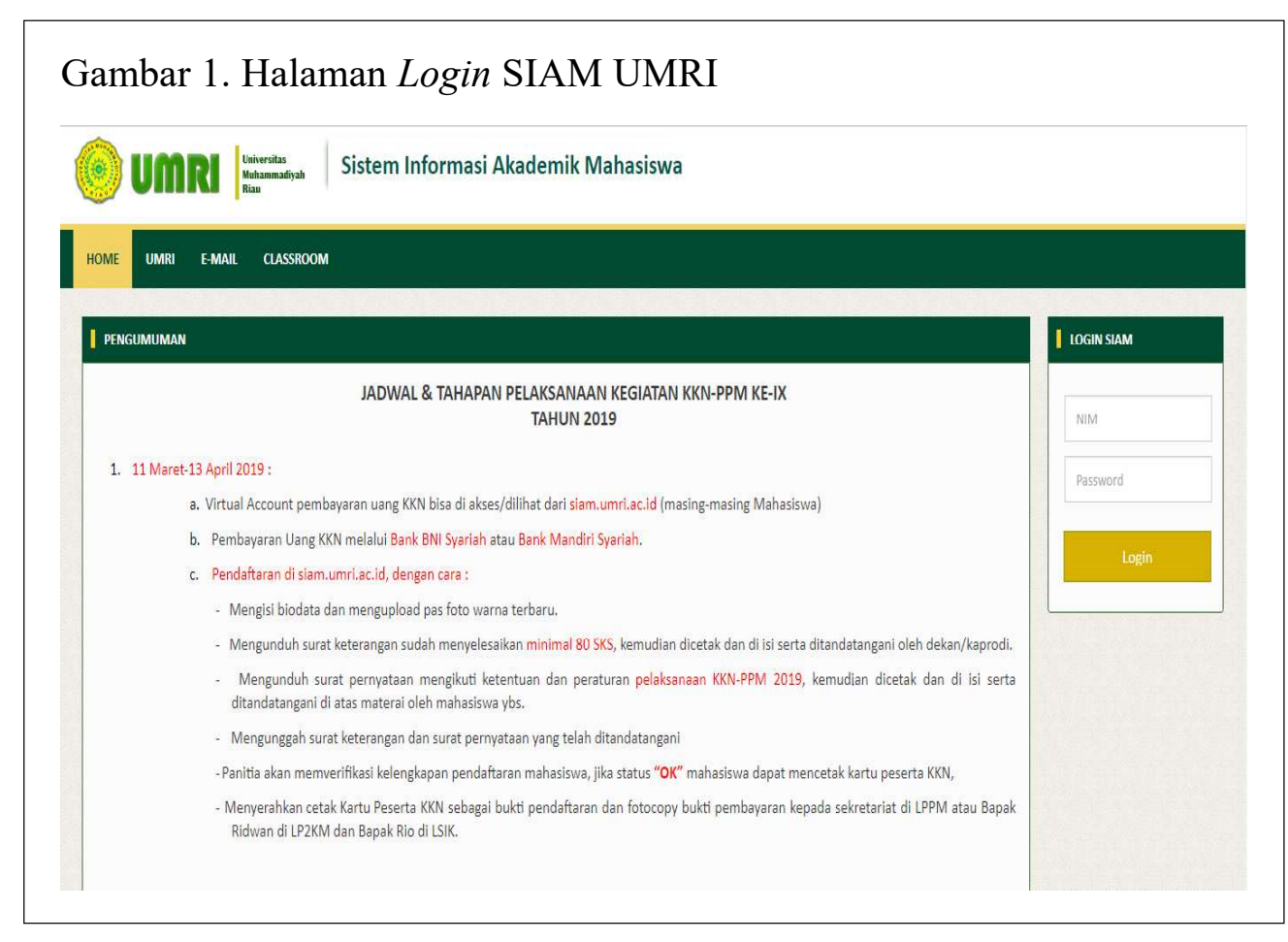


Kemudian dilakukan wawancara langsung dengan seorang staf TIPD UMRI untuk memperoleh informasi lebih lanjut mengenai permasalahan yang ada pada SIAM. Flow chart tahapan-tahapan penelitian ini disajikan pada Gambar 2.

Dalam menentukan sampel, peneliti menggunakan teknik random sampling dimana sampel akan diambil secara acak dari seluruh populasi yang ada yaitu 4.623 mahasiswa aktifpengguna SIAMUniversitas Muhammadiyah Riau. Jumlah dihitung dengan menggunakan rumus slovin dengan error tolerance sebesar 0,05 . Berdasarkan hasil perhitungan diperoleh jumlah sampel sebesar 369 mahasiswa aktif Universitas Muhammadiyah Riau.

SUS diciptakan sebagai skala yang quick and dirty untuk memenuhi kebutuhan akan kuesioner yang singkat dan reliable yang dikembangkan oleh John Brooke pada tahun 1986. SUS merupakan kuesioner yang dapat digunakan untuk mengukur usability sistem komputer menurut sudut pandang subyektif pengguna. Skala SUS umumnya digunakan setelah responden telah memiliki kesempatan untuk menggunakan sistem yang dievaluasi, tapi sebelum pembekalan atau diskusi berlangsung. Responden harus diminta untuk mencatat tanggapan langsung mereka untuk setiap item, daripada berpikir tentang item untuk waktu yang lama (Brooke, 1996).
Kuesioner SUS terdiri dari 10 item pertanyaan, yaitu: saya akan sering menggunakan atau mengunjungi situs ini, saya menilai situs ini terlalu kompleks (memuat banyak hal yang tidak perlu), saya menilai situs ini mudah dijelajahi, saya membutuhkan bantuan teknis untuk menggunakan atau menjelajahi situs ini, saya menilai fungsi atau fitur yang disediakan pada situs ini dirancang dan disiapkan dengan baik, saya menilai terlalu banyak inkonsistensi pada situs ini, saya merasa kebanyakan orang akan mudah menggunakan atau menjelajahi situs ini dengan cepat, saya menilai situs ini sangat rumit untuk dijelajahi, saya merasa sangat percaya diri menjelajahi situs ini, dan saya perlu belajar banyak hal sebelum saya dapat menjelajahi situs ini dengan baik

Kuesioner SUS menggunakan 5 poin skala Likert. Responden diminta untuk memberikan penilaian Sangat Tidak Setuju, Tidak Setuju, Netral, Setuju, dan Sangat Setuju pada 10 item pernyataan SUS sesuai dengan penilaian masing-masing responden. Jika responden merasa tidak menemukan skala respon yang tepat, responden harus mengisi titik tengah skala pengujian (Brooke, 1996). Setiap item pernyataan memiliki skor kontribusi dalam perhitungan. Setiap skor kontribusi item berkisar antara 0 hingga 4. Untuk item 1, 3, 5, 7, dan 9 yang berupa pernyataan positif skor kontribusinya 


\section{Gambar 2. Flow Chart Tahapan Penelitian}

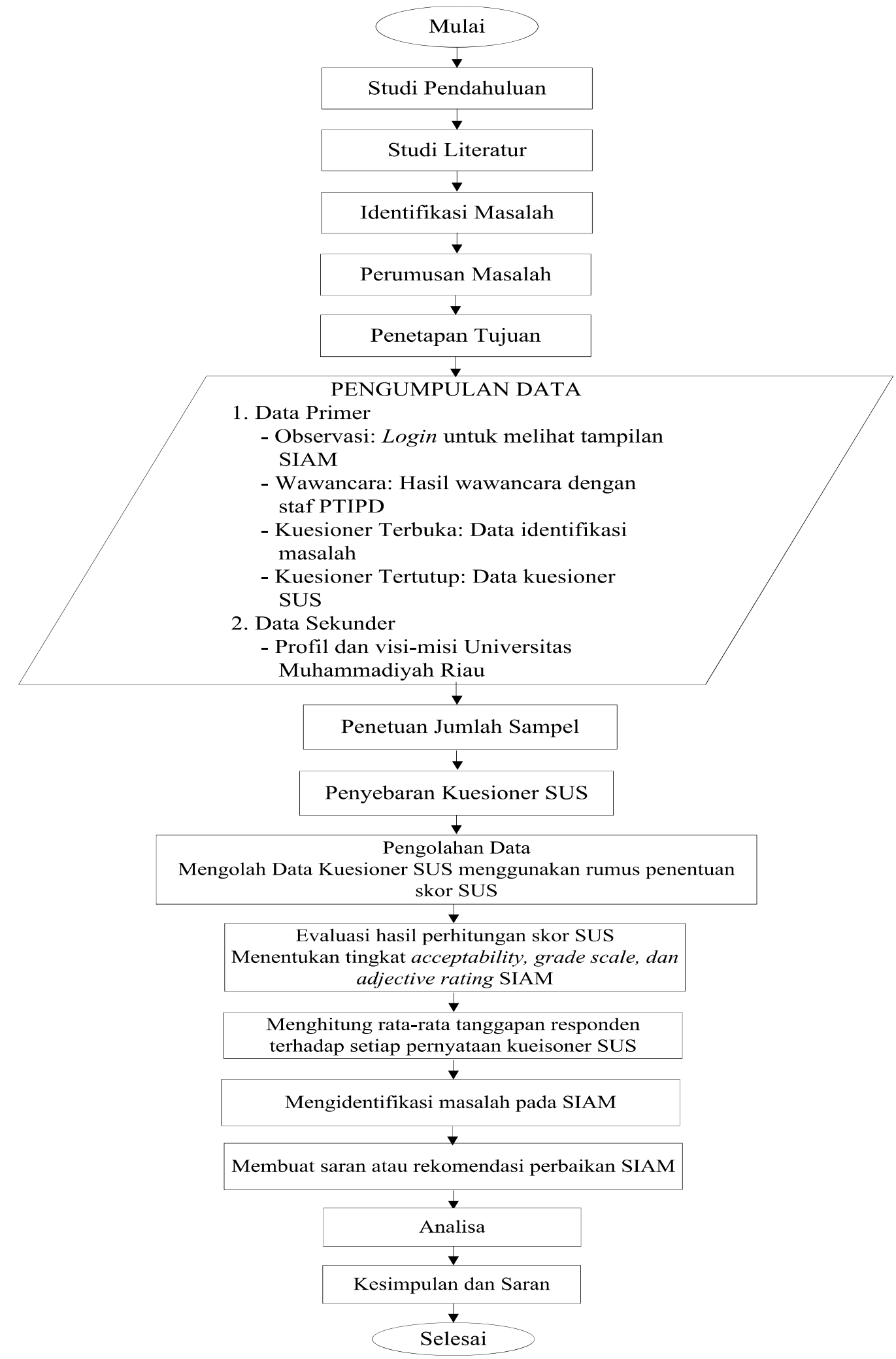


adalah skala dikurangi 1 . Untuk item 2, 4, 6,8 , dan 10 yang berupa pernyataan negatif skor kontribusinya adalah 5 dikurangi skala. Jumlah skor kontribusi dikali dengan 2,5 untuk mendapatkan nilai keseluruhan system usability. Gambar 3 menyajikan skor SUS berkisar dari 0 hingga 100 (Brooke, 1996). Berikut rumus perhitungan skor SUS:

Skor SUS $=((\mathrm{R} 1-1)+(5-\mathrm{R} 2)+(\mathrm{R} 3-1)+(5-$ R4) +(R5-1) + (5-R6) + (R7-1) + (5-R8) + $(\mathrm{R} 9-1)+(5-\mathrm{R} 10) \times 2.5)$

\section{HASIL DAN PEMBAHASAN}

Perhitungan skor SUS dilakukan dengan menggunakan rumus skor SUS. Berdasarkan perhitungan skor SUS diperoleh rata-rata skor SUS individual yaitu sebesar 27,27. Nilai SIAM berdasarkan skor SUS yang telah diperoleh adalah sebagai berikut: dalam pengukuran acceptability SIAM termasuk kedalam kategori acceptable atau dapat diterima oleh penggunanya, dalam pengukuran grade scale termasuk ke dalam kategori grade $\mathrm{C}+$, dalam pengukuran adjective rating termasuk kedalam kategori good, dan nilai SIAM berdasarkan percentile ranking adalah 63,343.

Untuk melakukan identifikasi masalah, terlebih dahulu dilihat rata-rata tanggapan responden terhadap kuesioner. Penentuan kategori rata-rata tanggapan responden dilakukan dengan menghitung interval kelas kemudian dilakukan klasifikasi ratarata tanggapan responden. Berdasarkan perhitungan diperoleh interval kelas 0,8 . Kriteria penilaian rata-rata jawaban responden yang disajikan pada Tabel 2 .

Tabel 2

Kategori Rata-rata dari Skor Interval

\begin{tabular}{cc}
\hline Interval & Kategori \\
\hline $4,2<\mathrm{a}=<5$ & Sangat Setuju \\
$3,4<\mathrm{a}=<4,2$ & Setuju \\
$2,6<\mathrm{a}=<3,4$ & Netral \\
$1,8<\mathrm{a}=<2,6$ & Tidak Setuju \\
$1<\mathrm{a}=<1,8$ & Sangat Tidak Setuju \\
\hline
\end{tabular}

Gambar 3. Skala SUS (Brooke, 2013)

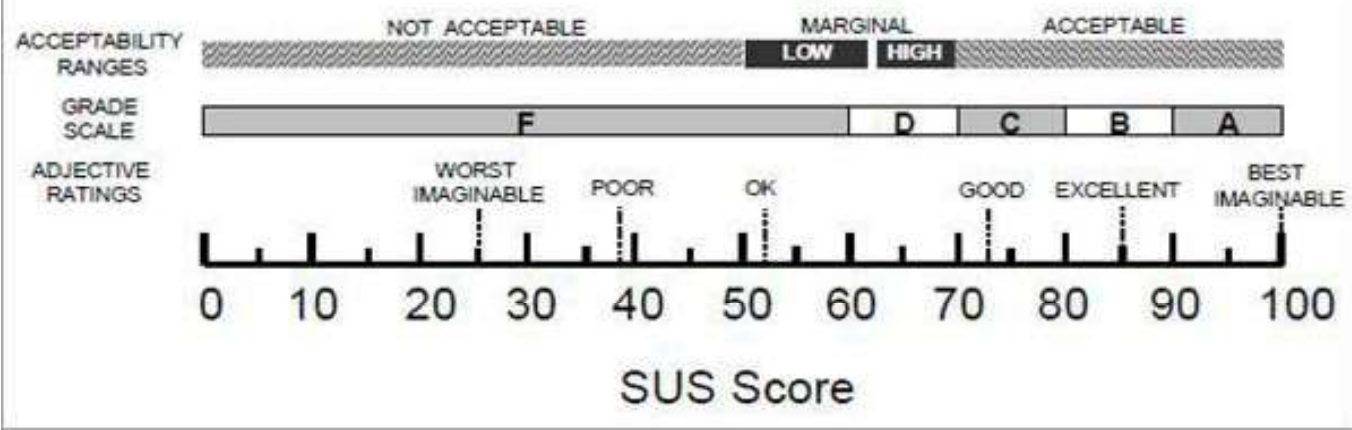


Berdasarkan kategori rata-rata pada Tabel 2, tanggapan responden terhadap masing-masing variabel pernyataan di kuesioner SUS disajikan pada Tabel 3.

Tabel 3 menunjukkan bahwa ratarata tanggapan responden terhadap setiap item pada kuesioner SUS. Pada pernyataan 5 "Saya menilai fungsi atau fitur yang disediakan pada situs ini dirancang dan disiapkan dengan baik" responden memberikan rata-rata tanggapan "Netral", dan pada pernyataan 6 "Saya menilai terlalu banyak inkonsistensi pada situs ini” responden memberikan rata-rata tanggapan "Setuju". Hal ini berarti bahwa sebagian responden tidak setuju jika fungsi dan fitur SIAM telah dirancang dengan baik, dan lebih dari sebagian responden menilai jika terdapat beberapa inkonsistensi pada SIAM. Dari penilaian responden tersebut, peneliti melakukan identifikasi permasalahan yang menyebabkan adanya penilaian yang tidak diharapkan terhadap SIAM. Adapun permasalahan dan penyebabnya dapat dilihat pada Tabel 4 dan 5.

Rekomendasi perbaikan SIAM diperoleh berdasarkan tanggapan responden pada kuesioner SUS yang mengacu kepada permasalahan atau kendala yang dialami pengguna SIAM. Setelah mengetahui penyebab dari permasalahan-permasalahan tersebut, dapat diperoleh beberapa rekomendasi atau saran perbaikan yang dapat dilihat pada Tabel 6 .

\section{Tabel 3}

Rata-rata Tanggapan Responden

\begin{tabular}{lcl}
\hline \multicolumn{1}{c}{ Pernyataan } & Mean & \multicolumn{1}{c}{ Kategori } \\
\hline $\begin{array}{l}\text { Saya akan sering menggunakan atau mengunjungi situs ini } \\
\text { Saya menilai situs ini terlalu kompleks (memuat banyak hal }\end{array}$ & 3,9 & Setuju \\
$\begin{array}{l}\text { yang tidak perlu) } \\
\text { Saya menilai situs ini mudah dijelajahi }\end{array}$ & Sangat Tidak Setuju \\
$\begin{array}{l}\text { Saya membutuhkan bantuan teknis untuuk menggunakan } \\
\text { atau menjelajahi situs ini }\end{array}$ & $\begin{array}{l}\text { Setuju } \\
\text { Saya menilai fungsi atau fitur yang disediakan pada situs ini }\end{array}$ & Sangat Tidak Setuju \\
$\begin{array}{l}\text { dirancang dan disiapkan dengan baik } \\
\text { Saya menilai terlalu banyak inkonsistensi pada situs ini }\end{array}$ & Netral \\
$\begin{array}{l}\text { Saya merasa kebanyakan orang akan mudah menggunakan } \\
\text { atau menjelajahi situs ini dengan cepat }\end{array}$ & 4,5 & Setuju \\
$\begin{array}{l}\text { Saya menilai situs ini sangat rumit untuk dijelajahi } \\
\text { Saya merasa sangat percaya diri menjelajahi situs ini }\end{array}$ & $\begin{array}{l}\text { Setuju } \\
\text { Saya perlu belajar banyak hal sebelum saya dapat }\end{array}$ & Sangat Tidak Setuju \\
menjelajahi situs ini dengan baik & 2,4 & Setuju \\
\hline
\end{tabular}


Tabel 4

Identifikasi Permasalahan pada SIAM

\begin{tabular}{cl}
\hline Pernyataan & \multicolumn{1}{c}{ Permasalahan } \\
\hline 5 & $\begin{array}{l}\text { 1. Link menu "Bantuan" tidak dapat memberi informasi cara penggu- } \\
\text { naan SIAM dan membantu mahasiswa ketika terjadi error }\end{array}$ \\
& $\begin{array}{l}\text { 2. Kegagalan saat mengisi KRS dan cetak kartu ujian } \\
6\end{array}$ \\
$\begin{array}{l}\text { 1. Jadwal perkuliahan yang tidak konsisten } \\
\text { 2. Mata kuliah yang tiba-tiba hilang } \\
\text { 3. Histori pembayaran uang kuliah tidak sinkron }\end{array}$ \\
\hline
\end{tabular}

Tabel 5

Penyebab Permasalahan pada SIAM

\begin{tabular}{|c|c|}
\hline Permasalahan & Penyebab \\
\hline $\begin{array}{l}\text { Link menu "Bantuan" tidak dapat } \\
\text { memberi informasi cara penggunaan } \\
\text { SIAM dan membantu mahasiswa ketika } \\
\text { terjadi error }\end{array}$ & $\begin{array}{l}\text { Link menu "Bantuan" pada SIAM hanya } \\
\text { langsung terkait dengan website UMRI }\end{array}$ \\
\hline Kegagalan saat mengisi KRS & $\begin{array}{l}\text { Server lambat dikarenakan terlalu banyak yang } \\
\text { mengakses SIAM di waktu yang bersamaan }\end{array}$ \\
\hline Jadwal perkuliahan yang tidak konsisten & $\begin{array}{l}\text { Kaprodi perlu menyesuaikan jadwal dosen jika } \\
\text { melibatkan dosen dari luar prodi karena jadwal } \\
\text { dosen tersebut sering bentrok dengan jadwal } \\
\text { yang sudah disiapkan oleh prodi. Penyesuaian } \\
\text { jadwal ini menjadi lebih lama dari jadwal input } \\
\text { yang sudah ditetapkan karena SIAM tidak dapat } \\
\text { mendeteksi jadwal yang bentrok. }\end{array}$ \\
\hline Mata kuliah yang tiba-tiba hilang & $\begin{array}{l}\text { 1. Adanya perubahan jadwal perkuliahan. } \\
\text { 2. Adanya perubahan kelas. } \\
\text { Perubahan kelas disebabkan oleh kuota jumlah } \\
\text { mahasiswa yang tertera pada SIAM tidak sesuai } \\
\text { dengan kapasitas ruang belajar mahasiswa } \\
\text { sehingga kaprodi memindahkan jadwal untuk } \\
\text { beberapa mahasiswa yang tidak mendapat ruang } \\
\text { belajar dengan cara melakukan penambahan } \\
\text { kelas. }\end{array}$ \\
\hline $\begin{array}{l}\text { Histori pembayaran uang kuliah tidak } \\
\text { sinkron }\end{array}$ & $\begin{array}{l}\text { Laporan pembayaran uang kuliah tidak } \\
\text { otomatis, bank membutuhkan waktu minimal } \\
24 \text { jam untuk mengupload laporan pembayaran }\end{array}$ \\
\hline
\end{tabular}


Analisis pada Sistem Informasi Akademik (Anggraini, W., dkk.)

Tabel 6

Saran Perbaikan SIAM

\begin{tabular}{|c|c|}
\hline Permasalahan & Saran Perbaikan \\
\hline $\begin{array}{l}\text { Link menu "Bantuan" tidak } \\
\text { dapat memberi informasi } \\
\text { cara penggunaan SIAM dan } \\
\text { membantu mahasiswa ketika } \\
\text { terjadi error }\end{array}$ & $\begin{array}{l}\text { Pengembang SIAM diharapkan dapat mengganti } \\
\text { penempatan link "Bantuan" tersebut. Seharusnya link } \\
\text { "Bantuan" berisi petunjuk penggunaan SIAM dan } \\
\text { pertolongan pada user yang mengalami error. }\end{array}$ \\
\hline Kegagalan saat mengisi KRS & $\begin{array}{l}\text { 1. Melakukan pembagian jadwal pengisian KRS yang } \\
\text { terstruktur (disarankan untuk fakultas teknik, fakultas } \\
\text { ekonomi, fakultas ilmu komputer, dan ilmu komunikasi } \\
\text { agar membagi jadwal pengisian KRS per program studi) } \\
\text { 2. Disarankan untuk melakukan penambahan bandwidth } \\
\text { jaringan sistem }\end{array}$ \\
\hline $\begin{array}{l}\text { Jadwal perkuliahan yang } \\
\text { tidak konsisten }\end{array}$ & $\begin{array}{l}\text { Perlu adanya perbaikan sistem oleh pihak pengembang } \\
\text { SIAM sehingga jadwal bentrok dapat terdeteksi. }\end{array}$ \\
\hline $\begin{array}{l}\text { Mata kuliah yang tiba-tiba } \\
\text { hilang }\end{array}$ & $\begin{array}{l}\text { 1. Perbaikan SIAM sehingga dapat mendeteksi jadwal } \\
\text { bentrok } \\
\text { 2. Pihak prodi perlu melaporkan kapasitas ruang } \\
\text { belajar kepada admin SIAM agar admin SIAM dapat } \\
\text { menyesuaikan kuota kelas dengan kapasitas ruang belajar } \\
\text { sehingga tidak ada lagi mahasiswa yang tidak mendapat } \\
\text { kelas. }\end{array}$ \\
\hline $\begin{array}{l}\text { Histori pembayaran uang } \\
\text { kuliah tidak sinkron }\end{array}$ & $\begin{array}{l}\text { Perlu adanya sosialisasi yang jelas oleh pihak fakultas } \\
\text { kepada mahasiswa untuk menjelaskan sistematika pem- } \\
\text { bayaran dan status pembayaran uang kuliah agar tidak } \\
\text { terjadi kesalahpahaman. }\end{array}$ \\
\hline
\end{tabular}

\section{SIMPULAN}

Berikutiniadalahkesimpulanyang dapat diambil dari penelitian ini. Pertama, nilai usability yang diperoleh dari perhitungan skor system usability scale adalah 72,27. Artinya, bahwa SIAM sudah "acceptable" atau dapat diterima oleh pengguna nya dan memiliki skala nilai $\mathrm{C}+$ dan memiliki rating "good" atau baik serta nilai percentile rank berada pada nilai 63,34. Kedua, berdasarkan perhitungan rata-rata tanggapan responden terhadap tiap item pernyataan kuesioner SUS dapat diketahui bahwa responden menilai jika fungsi dan fitur SIAM belum dirancang dengan baik dan SIAM memiliki banyak inkonsistensi. Penilaian ini muncul karena terdapat beberapa permasalahan pada SIAM yang disebabkan oleh beberapa hal, seperti link menu "Bantuan" pada SIAM hanya langsung terkait dengan website UMRI, kegagalan saat mengisi KRS yang disebabkan oleh server lambat, jadwal 
kuliah tidak konsisten dan mata kuliah sering hilang yang disebabkan oleh SIAM tidak dapat mendeteksi jadwal yang bentrok dan ketidaksesuaian kuota kelas yang tertera pada SIAM dengan kapasitas ruang belajar, dan permasalahan pada laporan pembayaran uang kuliah yang tidak otomatis.

Rekomendasi atau saran perbaikan yang dapat diberikan dalam penelitian ini adalah sebagai berikut. Pertama, pengembang SIAM diharapkan dapat menyesuaikan link "Bantuan" sesuai dengan nama dan tujuan link tersebut.Kedua, untuk fakultas yang memiliki jumlah mahasiswa banyak agar melakukan pembagian jadwal isi KRS per program studi dan melakukan penambahan bandwidth sistem jika diperlukan.Ketiga, melakukan pengembangan terhadap SIAM agar dapat mendeteksi jadwal bentrok. Keempat, disarankan agar kaprodi dan admin SIAM memiliki koordinasi yang baik dalam berbagi informasi kapasitas ruang belajar.Kelima, perlu adanya sosialisasi yang jelas terhadap mahasiswa untuk menjelaskan sistematika pembayaran dan status pembayaran uang kuliah agar tidak terjadi kesalahpahaman.

\section{DAFTAR PUSTAKA}

Aelani, K., \& Falahah. (2012). Pengukuran usability sistem menggunakan use questionnaire (Studi kasus: Aplikasi perwalian online STMIK "AMIK Bandung"). Seminar Nasional Aplikasi Teknologi Informasi, 2012.

Brooke, J. (1996). SUS: A "quick and dirty" usability scale. Dalam P. W. Jordan, B. Thomas, B. A. Weerdmeester, \& A. L. McClelland (Eds.), Usability evaluation in industry (pp. 189-194). London: Taylor and Francis.

Brooke, J. (2013). SUS: A retrospective. Journal of Usability Studies, 8(2).

H. N., I. A., Santoso, P. I., \& Ferdiana, R. (2015). Pengujian usability website menggunakan system usability scale. IPTEK-KOM, 17(1), 31-38.

Siagian, S. H. T., \& Effiyaldi, E. (2018). Analisis dan perancangan sistem informasi akademik pada Stikes Prima Jambi. Jurnal Manajemen Sistem Informasi, 3(4), 1282-1291.

Umri.."Universitas Muhammadiyah Riau". Online diakses pada tanggal 19 September 2018. http://umri.ac.id/.2018 Widiatmoko, M. E., Suyanto, M., \& Sofyan, A. F. (2015). Analisis sistem informasi dengan pendekatan usability (Studi Kasus Website STIMIK Amikom Yogyakarta). Jurnal Angkasa, 7(1). 